\title{
EFIKASI DIRI DAN MANAJEMEN DIRI PADA PASIEN DENGAN DIABETES TIPE 2: SEBUAH REVIEW SISTEMATIK
}

\author{
Neneng Astuti \\ Program Studi DIII Keperawatan, Fakultas MIPA dan Kesehatan, \\ Universitas Muhammadiyah Riau, Pekanbaru, Indonesia.
}

Email: go_ners@yahoo.com

\begin{abstract}
ABSTRAK
Pendahuluan: Diabetes merupakan penyakit yang bersifat swakelola, Keberhasilan pengelolaan diabetes bergantung pada aktivitas perawatan diri individu untuk mengontrol gejala dan menghindari komplikasi. Efikasi diri pada diabetes adalah keyakinan pasien terhadap kemampuannya untuk melakukan berbagai perilaku manajemen diri diabetes, dan manajemen diri pada diabetes merupakan tugas yang menantang yang membutuhkan perubahan gaya hidup jangka panjang, termasuk diet, minum obat, latihan fisik, maupun pemeriksaan kadar gula darah secara teratur.

Metode: Review sistematik dilakukan dengan penelusuran database elektronik yaitu, CINAHL dan ProQuest. Publikasi jurnal mulai dari tahun 2006-2013, dengan menggunakan kata kunci: diabetes tipe 2, efikasi diri, manajemen diri diabetes, dan perawatan diri diabetes. Review sistematik ini menggunakan kriteria seleksi untuk melakukan data extraction yaitu; jurnal bahasa Inggris, full text dan mencakup abstrak, metode penelitian kuantitatif, subjek diabetes tipe 2.

Hasil: Artikel terakhir yang digunakan dalam review sistematik ini sebanyak 12 artikel yang sesuai dengan kriteria seleksi. Dalam review sistematik ini menguraikan tentang definisi efikasi diri dan manajemen diri pada diabetes, instrumen penelitian yang digunakan, serta faktor-faktor yang berhubungan dengan manajemen diri pada diabetes tipe 2 .

Kesimpulan: Efikasi diri dan manajemen diri pada pasien diabetes merupakan dua komponen penting sebagai dasar untuk mencegah komplikasi terkait penyakit dan mempertahankan kualitas hidup pasien dengan diabetes tipe 2.
\end{abstract}

Kata Kunci: Diabetes tipe 2, efikasi diri, manajemen diri diabetes, dan perawatan diri diabetes

\section{PENDAHULUAN}

Diabetes melitus pada orang dewasa merupakan masalah kesehatan utama (Wu et al., 2007), dengan prevalensi yang semakin meningkat, sehingga menjadi pandemi (Hjlem et al., 2003; Al-Khawaldeh, Al-Hassan \& Froelicher, 2012). Diabetes memiliki dampak terhadap kehidupan individu, keluarga, dan sistem perawatan kesehatan. Kronisitas diabetes dan potensi komplikasi serius yang sering terjadi mengakibatkan beban keuangan dan penurunan kualitas hidup. Diabetes yang sering tidak terkontrol dapat mengakibatkan komplikasi seperti penyakit jantung, stroke, tekanan darah tinggi, kebutaan, penyakit ginjal, penyakit sistem saraf, amputasi kaki, dan kematian (AlKhawaldeh, Al-Hassan \& Froelicher, 2012).
Diabetes merupakan penyakit yang bersifat swakelola, karena pasien setidaknya $99 \%$ melakukan perawatan mereka secara mandiri (Feinglos \& Bethel, 2008; Gao et al., 2013). Untuk menormalkan kadar glukosa darah dan mengurangi mortalitas dan morbiditas terkait diabetes, pasien diabetes harus melakukan manajemen diri dalam kehidupan mereka seharihari termasuk minum obat, diet, olahraga, pemantauan glukosa darah, dan perawatan kaki (Shamoon et al., 1993; Xu et al., 2008). Tujuan utama dari manajemen pada diabetes adalah untuk mencegah komplikasi mikrovaskuler dan makrovaskuler, serta untuk menurunkan angka kematian dan biaya ekonomi akibat diabetes (Gao et al., 2013). Keberhasilan manajemen diri diabetes bergantung pada aktivitas perawatan diri individu untuk mengontrol gejala dan 
menghindari komplikasi. Jika kegiatan perawatan diri dilakukan secara teratur, maka dapat mencegah komplikasi yang timbul akibat diabetes (Wu et al., 2007).

Pada pasien dengan diabetes tipe 2, efikasi diri berperan penting dalam manajemen diri diabetes. Teori efikasi diri memberikan alasan ilmiah sebagai strategi yang memiliki potensi untuk meningkatkan kepercayaan diri individu terhadap kemampuannya untuk melakukan perubahan perilaku (Wu et al, 2007). Definisi ini menjelaskan bahwa efikasi diri individu berhubungan dengan situasi dan tugas tertentu, seperti manajemen perawatan diri pada diabetes tipe 2 (Lenz \& Shortridge-Baggett 2002; Sharoni \& Wu, 2012). Individu dengan tingkat efikasi diri yang tinggi memperkirakan akan sukses dalam pencapaian tujuan, sedangkan individu dengan tingkat efikasi diri yang rendah akan meragukan kemampuannya untuk mencapai tujuan (Hunt et al., 2012).

\section{METODOLOGI PENELITIAN}

Review sistematik ini dilakukan dengan penelusuran database elektronik yaitu CINAHL dan ProQuest. Publikasi jurnal mulai dari tahun 2006-2013, dengan menggunakan kata kunci: diabetes tipe 2, efikasi diri, manajemen diri diabetes, dan perawatan diri diabetes. Untuk menyaring jurnal penelitian dari barbagai database, maka digunakan kriteria seleksi untuk memilih bahan review sistematik yaitu: jurnal internasional dan berbahasa Inggris, full text dan original article, mencakup abstrak, metode penelitian kuantitatif, subjek diabetes tipe 2, dan menggunakan kuesioner standar.

\section{HASIL DAN PEMBAHASAN Hasil}

Artikel terakhir yang digunakan dalam review sistematik ini sebanyak 12 artikel yang sesuai dengan kriteria seleksi. Metode penelitian dari artikel yang digunakan dalam review sistematik ini secara keseluruhan menggunakan metode penelitian kuantitatif. Dari 12 artikel penelitian ini terdapat 8 artikel yang menggunakan pendekatan desain cross-sectional, 2 artikel dengan pendekatan desain korelasi, 1 artikel dengan pendekatan desain komparatif, dan 1 artikel dengan pendekatan desain gabungan korelasi dan komparatif.

Instrumen penelitian yang digunakan untuk mengukur efikasi diri pada diabetes tipe 2 dalam review sistematik ini yaitu 4 artikel menggunakan kuesioner Self-Efficacy Scale for Type 2 Diabetes, 2 artikel menggunakan kuesioner Diabetes Management Self-efficacy Scale (DMSES), 2 artikel menggunakan Chinese version of the Diabetes Management SelfEfficacy Scale (C-DMSES), 1 artikel menggunakan kuesioner Multidimensional Diabetes Questionnaire, dan 1 artikel menggunakan kuesioner Diabetes self-efficacy scale. Sedangkan instrumen penelitian yang digunakan untuk mengukur manajemen diri pada diabetes tipe 2 yaitu 8 artikel menggunakan kuesioner Summary of Diabetes Self Care Activities-Revised (SDSCA), 3 artikel menggunakan kuesioner Chinese Version of Summary of Diabetes Self Care ActivitiesRevised (SDSCA), dan 1 artikel menggunakan kuesioner Diabetes Self Care (DSC) Scale.

\section{Karakteristik Responden}

Artikel penelitian yang digunakan dalam review sistematik ini secara keseluruhan menggunakan penderita diabetes tipe 2 sebagai subjek penelitian. Karakteristik responden secara umum yang digunakan yaitu; umur, jenis kelamin, tingkat pendidikan, pekerjaan, status perkawinan, suku, agama, penghasilan, lama menderita diabetes, komplikasi diabetes, nilai $\mathrm{HbA}_{1 \mathrm{C}}$, Body Mass Index (BMI), program terapi, asuransi kesehatan, riwayat keluarga, dan edukasi yang diikuti atau yang pernah didapatkan.

\section{Efikasi Diri pada Diabetes}

Efikasi diri merupakan keyakinan individu tentang kemampuan pribadi terhadap kinerja perilaku. Dalam hal manajemen diri diabetes, efikasi diri adalah keyakinan pasien terhadap kemampuannya untuk melakukan berbagai perilaku manajemen diri diabetes (AlKhawaldeh, Al-Hassan, \& Froelicher, 2012). Efikasi diri merupakan dasar untuk meningkatkan efektivitas pendidikan diabetes karena berfokus pada perubahan perilaku (Van der Bijl \& Shortridge-Baggett, 2001; Wu et al., 2007). 
Efikasi diri adalah prediktor kuat terhadap manajemen diri diabetes. Seseorang yang hidup dengan diabetes yang memiliki tingkat efikasi diri yang lebih tinggi akan berpartisipasi dalam perilaku pengelolaan diri diabetes yang lebih baik (Hunt et al., 2012).

\section{Manajemen Diri pada Diabetes}

Manajemen diri (Self-management) dapat diartikan sebagai seperangkat keterampilan perilaku yang dilakukan dalam mengelola penyakit sendiri (Goodall \& Halford 1991; Wu et al., 2007). Xu et al. (2010) mendefinisikan manajemen diri pada diabetes merupakan seperangkat perilaku yang dilakukan oleh individu dengan diabetes untuk mengelola kondisi mereka, termasuk minum obat, mengatur diet, melakukan latihan fisik, pemantauan glukosa darah mandiri, dan mempertahankan perawatan kaki. Manajemen diri pada diabetes juga didefinisikan sebagai perilaku manajemen diri yang mencakup pengaturan pola makan, olahraga, pemantauan glukosa darah secara mandiri, dan minum obat, yang secara keseluruhan berhubungan dengan perbaikan yang signifikan dalam mengontrol status metabolik (Jones et al., 2003; Sousa et al., 2005; Hunt et al., 2012). Manajemen diri pada diabetes merupakan serangkaian rejimen yang rumit dan individu harus mengambil keputusan kritis untuk memahami cara menyeimbangkan obat, diet, dan olahraga untuk mencapai kontrol glikemik yang optimal (Xu, Pan \& Liu, 2010).

Faktor-faktor yang Berhubungan dengan Manajemen Diri pada Diabetes Tipe 2

a. Umur. Penderita diabetes yang lebih tua memiliki tingkat manajemen diri yang lebih tinggi pada diet, olahraga, dan perawatan kaki daripada individu yang lebih muda (Xu, Pan \& Liu, 2010). Penderita diabetes yang lebih tua dengan tingkat pendidikan yang lebih tinggi juga akan lebih baik dalam perawatan diri daripada orang tua yang buta huruf (Bai, Chiou \& Chang, 2009)

b. Tingkat pendidikan. Seseorang dengan pendidikan tinggi umumnya memiliki pemahaman yang baik tentang pentingnya perilaku perawatan diri dan memiliki keterampilan manajemen diri yang lebih baik untuk menggunakan informasi peduli diabetes yang diperoleh melalui berbagai media dibandingkan dengan tingkat pendidikan rendah (Bai, Chiou \& Chang, 2009). Seseorang dengan tingkat pendidikan yang lebih tinggi memiliki tingkat manajemen diri yang lebih tinggi terhadap diet, olahraga, dan pemeriksaan gula darah mandiri, dan lebih mudah untuk memahami informasi kesehatan yang berhubungan dengan diet, aktivitas fisik, dan pemeriksaan gula darah mandiri (Xu, Pan \& Liu, 2010).

c. Pekerjaan. Penderita diabetes yang bekerja memiliki tingkat manajemen diri lebih rendah untuk latihan fisik daripada penderita yang tidak bekerja. Penderita diabetes yang lebih muda yang bekerja bisa memiliki jadwal sibuk dan tanggung jawab yang sangat banyak, membuat perilaku manajemen diri diabetesnya seperti berolahraga, menjadi prioritas rendah bagi mereka (Xu, Pan \& Liu, 2010).

d. Efikasi diri. Seseorang yang hidup dengan diabetes tipe 2 yang memiliki tingkat efikasi diri yang lebih tinggi lebih berpartisipasi dalam perilaku manajemen diri diabetes. Efikasi diri yang lebih tinggi lebih mungkin untuk menunjukkan pengaturan diet secara optimal, olahraga, monitoring glukosa darah mandiri, dan perawatan kaki (Sarkar, Fisher \& Schillinger, 2006; Xu et al., 2008; Hunt et al., 2012).

e. Lamanya menderita diabetes. Seseorang dengan durasi penyakit lebih lama memiliki pengalaman dalam mengatasi penyakit mereka dan melakukan perilaku perawatan diri yang lebih baik (Wu et al., 2007). Seseorang yang telah didiagnosis dengan diabetes bertahun-tahun dapat menerima diagnosis penyakitnya dan rejimen pengobatannya, serta memiliki adaptasi yang lebih baik terhadap penyakitnya dengan mengintegrasikan gaya hidup baru dalam kehidupan mereka sehari-hari (Xu, Pan \& Liu, 2010).

f. Dukungan sosial. Dukungan sosial merupakan prediktor penting dalam perilaku perawatan diri pada pasien diabetes. Ketika 
pasien didiagnosis dengan penyakit kronis, maka pasien tersebut memerlukan bantuan perawatan dari teman dan keluarga. Pasien diabetes tipe 2 melakukan perilaku perawatan diri yang lebih baik ketika mereka menerima dukungan dari keluarga dan teman-temannya (Bai, Chiou \& Chang, 2009).

g. Asuransi. Penderita diabetes yang tidak memiliki asuransi kesehatan biasanya memiliki perilaku kurang baik dalam minum obat dan memantau kadar glukosa darah mereka secara teratur (Xu, Pan \& Liu, 2010).

h. Komunikasi antara pasien dan provider. Tujuan utama komunikasi antara pasien dan provider adalah untuk bertukar informasi tentang penyakit dan perawatannya. Sebuah gaya komunikasi yang positif dapat meningkatkan pemahaman pasien dan mengingat informasi tentang penyakit (Ong et al., 1995; Xu et al., 2008). Interaksi antara pasien dan provider dapat memperkuat kepercayaan pasien dan dapat mempengaruhi hasil kesehatan (Kaplan, Greenfield \& Ware, 1989; Xu et al., 2008). Komunikasi antara pasien dan provider yang lebih baik dapat membantu membangun hubungan saling percaya, dan menjadi landasan bersama untuk mempromosikan manajemen diri pasien dengan diabetes (Xu et al., 2008).

i. Jenis layanan perawatan. Pasien diabetes yang menerima perawatan dari spesialis menunjukkan kecenderungan yang lebih besar untuk melaksanakan praktek perawatan diri yang lebih baik termasuk gaya hidup yang lebih baik, dan mengontrol diabetes lebih baik daripada pasien yang menerima perawatan dokter umum. Para pasien yang menerima perawatan dari spesialis cenderung untuk berolahraga lebih banyak dan mengurangi merokok. Pada pasien yang mengunjungi dokter umum selama satu tahun terakhir lebih sering memiliki kecenderungan untuk menunjukkan kontrol glikemik yang buruk (Goudswaard et al.; Lee, Ahn \& Kim, 2009). Pasien yang telah menerima pendidikan tentang perawatan kaki diabetes dan pemeriksaan kaki oleh spesialis secara signifikan lebih mungkin untuk memeriksa kaki mereka secara teratur dan cenderung untuk mematuhi pedoman perawatan diabetes, serta menjaga kadar glukosa darah dalam tingkat optimal daripada pasien yang menerima perawatan dari dokter umum (De Berardis et al., 2005; Lee, Ahn \& Kim, 2009)

j. Bahasa dan budaya. Keterbatasan bahasa dan budaya pada materi pendidikan manajemen diri pada diabetes yang tepat dan program yang tersedia untuk pasien dengan diabetes, misalnya pada etnis Cina-Amerika. Kebanyakan program pendidikan manajemen diri pada diabetes tersedia dalam bahasa Inggris dan didasarkan pada budaya Barat, seperti jenis pilihan makanan dan membaca label, sehingga menyulitkan pasien diabetes Cina-Amerika untuk mengikuti program tersebut (Xu, Pan \& Liu, 2010).

k. Kepercayaan terhadap efektivitas pengobatan. Kepercayaan terhadap efektivitas pengobatan merupakan faktor penting yang mempengaruhi manajemen diri diabetes. Xu et al. (2008), mengungkapkan bahwa pada pasien Cina dapat menggunakan pendekatan medis Barat untuk mengontrol diabetes mereka, sementara untuk strategi manajemen penyakit, mereka lakukan berdasarkan tradisi pengobatan Cina. Kepercayaan dalam pengobatan Cina dapat mengurangi kepercayaan pasien dalam efektivitas pengobatan medis Barat untuk diabetes

\section{Pembahasan}

Review sistematik ini melihat deskripsi efikasi diri dan manajemen diri pada diabetes tipe 2 dan dari artikel review menunjukkan bahwa efikasi diri merupakan komponen penting yang mempengaruhi perilaku manajemen diri pada diabetes tipe 2. Efikasi diri yang kuat akan berhubungan positif terhadap partisipasi dalam perilaku manajemen diri pada diabetes (Sarkar, Fisher \& Schillinger, 2006; Bean, Cundy \& Petrie, 2007; Wu et al., 2007; Xu et al., 2008; Lee, Ahn \& Kim., 2009; Hunt et al., 2012; Sharoni \& Wu, 2012; Al-Khawaldeh, Al-Hassan \& Froelicher, 2012; Gao et al., 2013).

Masalah utama dalam pengelolaan diabetes adalah sikap pasien terhadap penyakitnya, karena 
pasien memiliki ide dan keyakinan yang berbeda. Perubahan perilaku dan gaya hidup biasanya sulit dilakukan bagi penderita diabetes (Rapley \& Fruin, 1999; Wu et al., 2007). Meskipun perilaku dalam mengontrol diabetes ini sangat penting, akan tetapi perilaku manajemen diri tidak dilakukan secara konsisten oleh pasien diabetes (Xu et al., 2008). Dan meskipun pasien mendapatkan pengetahuan tentang manajemen perawatan diri untuk penyakitnya, akan tetapi perubahan perilaku dan gaya hidup biasanya sulit dilakukan bagi penderita diabetes (Rapley \& Fruin, 1999; Wu et al., 2007), pasien tidak selalu menerapkan perubahan perilaku yang diinginkan (Sharoni \& Wu, 2012).dan banyak penderita diabetes yang tidak terlibat dalam semua praktik manajemen diri (Sarkar, Fisher \& Schillinger, 2006; $\mathrm{Xu}$ et al., 2008; Hunt et al., 2012; AlKhawaldeh, Al-Hassan \& Froelicher, 2012).

Rekomendasi penelitian ke depan lebih menekankan pada pemberikan edukasi secara komprehensif, serta mengevaluasi kontrol glikemik pada pasien diabetes tipe 2. Hal ini dapat meningkatkan efikasi diri pasien serta meningkatkan kemandirian dan mempertahankan kemampuan pasien dalam melakukan manajemen diri pada penyakitnya.

\section{KESIMPULAN DAN SARAN}

Efikasi diri merupakan salah satu aspek yang diperlukan bagi pasien diabetes tipe 2 untuk meningkatkan kemandirian pasien dalam mengelola penyakitnya, dan manajemen diri merupakan bagian terpenting dari perawatan diabetes, karena manajemen diri pada diabetes menggabungkan antara faktor perilaku, faktor individu, dan dan faktor lingkungan ke dalam kegiatan sehari-hari yang telah direkomendasikan untuk pasien diabetes. Efikasi diri dan manajemen diri pada pasien diabetes merupakan dua komponen penting sebagai dasar untuk mencegah komplikasi terkait penyakit dan mempertahankan kualitas hidup. Perubahan perilaku dan gaya hidup biasanya sulit dilakukan bagi penderita diabetes, sehingga diperlukan pendekatan yang komprehensif dalam mengembangkan program perubahan perilaku yang melibatkan faktor-faktor tersebut.

\section{DAFTAR PUSTAKA}

Al-Khawaldeh, O. A., Al-Hassan, M. A., \& Froelicher, E.S. (2012). Self-efficacy, self-management, and glycemic control in adults with type 2 diabetes mellitus. Journal of Diabetes and Its Complications, 26, 10-16. doi:10.1016/j.jdiacomp.2011.11.002.

Bai Y-L, Chiou, C-P., \& Chang, Y-Y. (2009). Self-care behaviour and related factors in older people with type 2 diabetes. Journal of Clinical Nursing, 18, 33083315 doi: $\quad 10.1111 / \mathrm{j} .1365$ 2702.2009.02992.x.

Bean, D., Cundy, T., \& Petrie, K. J. (2007). Ethnic differences in illness perceptions, self-efficacy and diabetes self-care. Psychology and Health; 22(7), 787-811. doi: 10.1080/14768320600976240.

Gao, J., Wang, J., Zheng, P., Haardörfer, R., Kegler, M. C., Zhu, Y., \& Fu, H. (2013). Effects of self-care, self-efficacy, social support on glycemic control in adults with type 2 diabetes. BMC Family Practice, 14, 66. doi: 10.1186/14712296-14-66.

Hunt, et al. (2012). Relationships among selfefficacy, social support, social problem solving, and self-management in a rural sample living with type 2 diabetes mellitus. Research and Theory for Nursing Practice: An International Journal, 26(2). doi: 10.1891/15416577.26.2.126.

Lee, H., Ahn, S., \& Kim, Y. (2009). Self-care, self-efficacy, and glycemic control of koreans with diabetes mellitus. Asian Nursing Research, 3(3), 139-146. doi: 10.1016/S1976-1317(09)60025-6.

Nyunt, S. W., Howteerakul, N.,Suwannapong, N., \& Rajatanun, T. (2010). Selfefficacy, self-care behaviors and glycemic control among type- 2 diabetes patients attending two private clinics in Yangon, Myanmar. Southeast Asian J Trop Med Public Health, 41(4). http://search.proquest.com/docview/7467 77410 ? accountid $=50257$ 
Sarkar, U., Fisher, L., \& Schillinger, D. (2006). Is self-efficacy associated with diabetes self-management across race/ethnicity and health literacy?. Diabetes Care, 29, 823-829. doi: 10.2337/diacare.29.04.06.dc05-1615.

Sharoni, S. K .A. \& Wu, S. F. V. (2012). Selfefficacy and self-care behavior of Malaysian patients with type 2 diabetes a cross sectional survey. Nursing and Health Sciences, 14, 38-45. doi: 10.1111/j.1442-2018.2011.00658.x.

Wu S-F. V., Courtney, M., Edwards, H., Mcdowell, J., Shortridge-bagget, L.M., \& Chang, P-J. (2007). Self-efficacy, outcome expectations and self-care behaviour in people with type 2 diabetes in Taiwan.Journal of Nursing and Healthcare of Chronic Illness in association with Journal of Clinical Nursing, 16(11c), 250-257. doi: 10.1111/j.1365-2702.2006.01930.x.

Xu, Y., Pan, W., \& Liu, H. (2010). Selfmanagement practices of Chinese Americans with type 2 diabetes. Nursing and Health Sciences, 12, 228-234. doi: 10.1111/j.1442-2018.2010.00524.x.

Xu, Y., Toobert, D., Savage, C., Pan, W., \& Whitmer, K. (2008). Factors Influencing Diabetes Self-Management in Chinese People With Type 2 Diabetes. Research in Nursing \& Health, 31, 613-625. doi:10.1002/nur.20293. 